\title{
Kahve ile Renklendirmenin Kompozit Rezinlerde Renk Stabilitesi ve Translusensi Parametresi Üzerindeki Etkisinin Değerlendirilmesi
}

\author{
Evaluation Of The Effect Of Coloration With Coffee On Color Stability And \\ Translucency Parameter In Composite Resins
}

\author{
Muhammet FIDAN*1 (D) \\ muhammetfidan93@gmail.com
}

\author{
Nurcihan YEŞILIRMAK ${ }^{1}$ (D) \\ nrchnyslrmk@gmail.com
}

Makbule Tuğba TUNÇDEMİR ${ }^{1}$ (D)

makbule.erkan@hotmail.com

\section{öz}

Amaç: Bu in vitro çalışmanın amacı; kahvede bekletmenin farklı kompozit rezinlerde renk değişimi ve translusensi parametresi (TP) üzerindeki etkisini değerlendirmektir.

Gereç ve Yöntemler: Çalışmada, üç farklı kompozit rezinden (Estelite $\Sigma$ Quick, G-Aenial Anterior; Omnichroma) toplamda 45 örnek (her kompozit rezinden 15 örnek) hazırlandı. Bașlangıç ve 12 gün kahvede bekletmenin ardından renk ölçümleri bir spektrofotometre ile yapıldı. Renk değişimleri $\left(\Delta \mathrm{E}_{00}\right)$ ve translüsensi parametresi $\left(\mathrm{TP}_{00}\right) \mathrm{CIEDE}_{2000} \mathrm{renk}$ formülü kullanılarak belirlendi. Veriler tek yönlü varyans analizi (One-way ANOVA), faktöriyel ANOVA ve t testi ile istatistiksel analize tabi tutuldu $(\mathrm{p}<0.05)$.

Bulgular: Kompozit rezin örneklerde 12 gün kahvede bekletme sonrası klinik olarak fark edilebilir renk değişimi $\left(\Delta \mathrm{E}_{00}\right.$; 3.28-6.28) gözlendi. En yüksek renk değişimi Omnichroma grubunda, en düşük renk değişimi ise Estelite $\Sigma$ Quick grubunda belirlendi $(\mathrm{p}<0.05)$. Omnichroma grubu, kahvede bekletme önce ve sonrasında değerlendirilen diğer kompozitler arasında en yüksek TP değerleri gösterdi $(\mathrm{p}<0.05)$. Omnichroma grubunun TP değeri artarken, diğer gruplarda TP değerlerinde azalma gözlendi. Kahve ile renklendirme sonrası Estelite $\Sigma$ Quick grubunun TP değerleri değișiklik göstermedi.

Sonuç: Kahve ile renklendirme kompozit rezinlerde renk ve translusensi değişikliğine neden oldu. Materyal içeriklerinin, optik özelliklerde etkili olduğu belirlendi. Restoratif materyalin optik özellikleri, restorasyonların renk stabilitesi için önemlidir.

Anahtar Kelimeler: Kompozit rezin, Renk stabilitesi, Translusensi parametresi

Geliş: 23.02.2021

Kabul: 27.04 .2021

Yayın: 30.04.2021

\begin{abstract}
Aim: The aim of this in vitro study was to evaluate the effect of coffee immersion on color and translucency parameter (TP) change in different composite resins.

Material and Methods: A total of 45 samples (15 samples from each composite resin) were prepared from three different composite resins (Estelite $\Sigma$ Quick; G-Aenial Anterior; Omnichroma). Color measurements were made by a spectrophotometer at the beginning and after 12 days in coffee immersion. Color changes $\left(\Delta \mathrm{E}_{00}\right)$ and translucency parameter $\left(\mathrm{TP}_{00}\right)$ were determined by CIEDE 2000 formula. The data were analyzed with one-way analysis of variance (One-way ANOVA), factorial ANOVA and t test ( $p<0.05)$.

Results: Clinically noticeable color change $\left(\Delta \mathrm{E}_{00}: 3.28-6.28\right)$ was observed in composite resin samples after 12 days in coffee immersion. The highest color change was detected in Omnichroma group and the lowest color change was detected in Estelite $\Sigma$ Quick group ( $\mathrm{p}<0.05)$. Omnichroma group showed the highest TP values among the materials before and after immersion in coffee $(\mathrm{p}<0.05)$. TP value of Omnichroma group was increased, while other composite groups decreased. TP values of the Estelite $\Sigma$ Quick did not change after immersion in coffee.

Conclusion: Coffee immersion caused color and translucency changes on composite resins. The optical properties of the materials were related to the material content. The optical properties of the restorative materials are important for the color stability of restorations.
\end{abstract}

Keywords: Color stability, Composite resin, Translucency parameter

$\begin{array}{lll}\text { Received: 23.02.2021 Accepted: 27.04.2021 Published: } 30.04 .2021 & \text { A }\end{array}$

Atıf / Citation: Fidan M, Yeşilırmak N, Tunçdemir MT. Kahve ile renklendirmenin kompozit rezinlerde renk stabilitesi ve translusensi parametresi üzerindeki etkisinin değerlendirilmesi. NEU Dent J. 2021;1:26-32.

* Sorumlu Yazar / Corresponding Author

1. Necmettin Erbakan Üniversitesi Diş Hekimliği Fakültesi Restoratif Diș Tedavisi AD

Konya, Türkiye 


\section{Gíriș}

Hastaların estetik restorasyonlara olan talebinin artması, uygun optik özelliklere sahip dental materyallerin geliştirilmesini sağlamıștır. ${ }^{1}$ Bir restorasyonun estetik başarısı, doğrudan optik görünümüyle ilgilidir. Estetik restorasyonların translusensi ve renk parametreleri önemli optik özelliklerdendir. Uygulanan restoratif materyaller, doğal diş yapısının hem rengini hem de translusensini taklit edebilmeli ve uzun dönemde renklenmelere karşı dirençli olabilmelidir. ${ }^{2}$

Renk değișikliği, materyalin derin tabakalarındaki fiziko-kimyasal reaksiyonlar sonucu oluşan iç faktörler ve yüzey boyayıcıların kompozit rezinin dış yüzeyinde birikmesi ve absorpsiyonu sonucu oluşan dış faktörler kaynaklı olabilmektedir. ${ }^{3}$ Kahve, şarap, kola gibi renklendirici sıvılardaki pigmentlerin absorpsiyonu kompozit rezinin renklenmesine neden olmaktadır. ${ }^{4}$ Kahve, kompozit rezinlerin içeriğindeki organik faza penetre olabilen ve renklenmeye neden olabilecek düşük polariteli sarı pigmentleri salma özelliğine sahip bir renklendirici ajan olarak değerlendirilmektedir. ${ }^{5}$

Renk algısı hem bireyler arasında hem de bir birey içinde farklı zamanlarda farklılaşan psikofiziksel bir fenomendir. ${ }^{6}$ Günümüzde doğal diş ve renk skalalarındaki renklerin analiz edilmesi için çoğunlukla konvansiyonel yöntem (diş renginin gözle belirlenmesi) ve dijital renk ölçümü (kolorimetre, spektroradyometre, spektrofotometre, dijital kameralar) olmak üzere çoğunlukla iki yöntem kullanılır. ${ }^{7}$ Renk ölçüm cihazlarıyla daha objektif, tekrarlanabilir ve hızlı ölçümler yapılmaktadır.7 Dijital cihazlar, standart bir renk ölçümü sağlayabildikleri için geleneksel sistemlerden daha güvenilir sonuçlar sağlar. ${ }^{8}$ Spektrofotometre, renk seçimi yapılırken öznel hataları ortadan kaldırmada önemli bir avantaja sahiptir. ${ }^{6}$ Sistematik bir derlemede spektrofotometre ile renk seçiminin daha doğru sonuçlar verdiği belirtilmektedir. ${ }^{9}$

Renk eşleştirmeleri geleneksel olarak renk kılavuzları ile gerçekleştirilmesine rağmen, spektrofotometreler renklerin sayısal ifadeleriyle standartlaştırılmış, nesnel ve doğru ölçümler sağladıkları için popüler bir renk eşleștirme aracı haline gelmiştir. ${ }^{10}$ Translusensi, bir materyalin ışığı geçirme durumu olarak tanımlanır. Translusensi parametresi (TP), dental materyallerin yarı saydamlığını değerlendirmek için kullanılmaktadır. ${ }^{1}$ TP, siyah ve beyaz zeminlerde materyaldeki renk farklılıklarının ölçülmesidir. ${ }^{11}$ CIELAB formülünü düzeltmeyi ve iyileștirmeyi amaçlayan Commission Internationale de l'Éclairage (CIE), ${ }^{12}$ CIEDE 2000 formülünün kullanılmasını önermiştir. Bununla birlikte, şu anda diş hekimliği literatüründeki translusensi çalışmalarının çoğunda, TP hala CIELAB renk uzay alanı ve bununla ilişkili renk formülü kullanılarak ölçülmektedir. Bu nedenle, TP tayini, farklı kompozit rezinlerin rengine, kalınlığına, matriks bileşimi; dolgu partikül boyutu ve içeriği ve kullanılan opaklaştırıcıların türü ve miktarına bağlı olarak farklılıklar göstermiștir. ${ }^{1}$

Translusensi değerinin sıfır olması materyalin opak olduğunu gösterir. TP değerinde artış, translüsens özelliğin de artması anlamına gelir. ${ }^{13}$ Diş minesi translüsens olduğundan estetik bir restorasyon için seçilecek materyalin de diş minesine benzer şekilde translüsensi özelliğe sahip olması önemlidir. Translüsensi, kompozit rezin restorasyonlarda başlıca önemli optik özelliklerden birisidir. Işığın yansıma miktarı ve kalitesini göstermektedir. ${ }^{11}$ Farklı kompozit rezinlerde polimerizasyon ve yaşlandırma sonrası bazı materyallerin translusensi değerlerinde artıș, bazılarında ise azalma olduğu belirtilmektedir. ${ }^{14}$ Estetiğin önemli olduğu anterior bölge restorasyonlarında tercih edilecek kompozit rezinlerde polimerizasyon sonrası renk ve translusensi değerlerinde değişiklik görülebileceği dikkate alınmalıdır. ${ }^{15}$

Bu kapsamda çalışmanın amacı; kahve ile renklendirmenin kompozit rezinlerde renk değişimine ve TP’ne etkisini araştırmaktır. Çalışmanın sıfır hipotezi, kahve ile renklendirmenin kompozit rezin örneklerde renk değişimine ve TP üzerinde etki göstermeyeceği yönündedir.

\section{GEREÇ ve YÖNTEMLER}

Bu çalışmada 3 farklı kompozit rezin (Estelite $\Sigma \mathrm{Qu}$ ick (A2), Tokuyama Dental, Tokyo, Japan; G-Aenial Anterior (A2), GC Corp, Tokyo, Japan; Omnichroma, Tokuyama Dental, Tokyo, Japan) kullanıldı (Tablo 1). Kompozit rezin örnekler, $8 \mathrm{~mm}$ çapında ve $2 \mathrm{~mm}$ derinliğinde disk şeklinde teflon kalıplar kullanılarak hazırlandı. Kompozit rezinler kalıba tek bir seferde el aletleri yardımı ile yerleștirildi. Bir siman camı ve onun üzerine şeffaf bant yerleştirilerek hafifçe basınç uygulandı. Cam plakalar kaldırıldıktan sonra LED ışık cihazıyla (Woodpecker LED.E (P), Guilin Woodpecker Medical Instrument Co., Guilin, Guangxi, China) yaklaşık $1200 \mathrm{~mW} / \mathrm{cm}^{2}$ güç yoğunluğunda 40 sn polimerize edildi. Her gruptaki örneklerin tek bir yüzeyine bir polisaj sistemi (OptiDisc, KerrHawe, Bioggio, Switzerland) uygulandı. Kompozit rezin gruplardan her bir grupta 15 adet örnek olmak üzere toplam 45 adet disk şeklinde örnek hazırlandı. Örnekler 24 saat oda sıcaklığında bekletildikten sonra bütün kompozit rezin örneklerin başlangıç renk değerleri bir spektrofotometre (Lovibond RT Series, Tintometer Group, İngiltere) ile yapıldı. Her örnekten üç ölçüm yapılıp ortalaması alınarak L*a*b* değerleri kaydedildi. D65 standartlarında aydınlatma şartlarında renk ölçümleri beyaz zeminde, TP için siyah ve beyaz zeminde ve her ölçüm öncesi cihaz kalibre edilerek ölçümler geçekleştirildi. Daha sonra örnekler $300 \mathrm{ml}$ lik kay- 
nayan suya 3,6 gr kahve eklenerek elde edilen solüsyon içerisinde 12 gün bekletildi. ${ }^{16}$ Renklendirmenin ardından bir dakika boyunca distile suda yıkanıp kurutulan örneklerden ikinci renk ölçümleri CIEDE 2000 renk formülü (Şekil 1) kullanılarak hesaplandı. Formülde belirtilen $\Delta \mathrm{L}^{\prime}, \Delta \mathrm{C}^{\prime}$ ve $\Delta \mathrm{H}^{\prime}$ birbirinden ayrı 2 ölçüm arasındaki aydınlık (lightness), renk yoğunluğu (chroma) ve renk tonu (hue) farklarını tanımlar. $S_{L}, S_{C}$ ve $S_{H}$ renk yoğunluğu ve renk tonuna ait ağırlık fonksiyonlarını ifade eder. $\mathrm{R}_{\mathrm{T}}$; renk sistemindeki mavi alandaki renk yoğunluğu ve renk tonu farklılıkları arasındaki etkileşim miktarını tanımlayan devir fonksiyonudur. $\mathrm{K}_{\mathrm{L}^{\prime}}, \mathrm{K}_{\mathrm{C}}$ ve $\mathrm{K}_{\mathrm{H}}$ aydınlık, renk yoğunluğu ve renk tonu için değerlendirilen parametrik faktörlerdir. $^{17}$

Örneklerin TP değerlerinin ( $\left.\mathrm{TP}_{00}\right)$ hesaplanması CIEDE 2000 renk formülü (Şekil 2) kullanılarak gösterildi. Formülde belirtilen "B" ve "W" alt simgelerinin renk koordinatlarına karşıllı geldiği yer sırasıyla siyah ve beyaz arka planlardır. $\left(\mathrm{L}_{B}-\mathrm{L}_{W}\right),\left(\mathrm{C}_{B}-\mathrm{C}_{\mathrm{W}}\right)$ ve $\left(\mathrm{H}_{\mathrm{B}}-\right.$ $\mathrm{H}_{\mathrm{w}}$ ) örneklerde siyah ve beyaz zeminlerdeki sırasiyla lightness, chroma ve hue tonu farklarıdır. RT; renk sisteminde yer alan mavi alandaki renk yoğunluğu ve renk tonu farklılıkları arasındaki etkileșim miktarını gösteren devir fonksiyonudur. Ağırlıklandırma fonksiyonları $\mathrm{S}_{\mathrm{L}}, \mathrm{S}_{\mathrm{C}}, \mathrm{S}_{\mathrm{H}} ; \mathrm{L}$, a, b koordinatlarında B (siyah) ve W (beyaz) arka planlar üzerinde renk farkı konumunun varyasyonları için toplam renk farklılığını ayarlar. $K_{L}, K_{C}$ ve $K_{H}$ ise aydınlık, renk yoğunluğu ve renk tonu için hesaplanan parametrik faktörlerdir. Bu çalışmada parametrik faktörler 1 olarak belirlendi. $^{1}$

Şekil 1: CIEDE 2000 renk formülü $\left(\Delta \mathrm{E}_{00}\right)^{18}$

$$
\begin{aligned}
\Delta E_{00}= & {\left[\left(\frac{\Delta L^{\prime}}{K_{L} S_{L}}\right)^{2}+\left(\frac{\Delta C^{\prime}}{K_{C} S_{C}}\right)^{2}+\left(\frac{\Delta H^{\prime}}{K_{H} S_{H}}\right)^{2}\right.} \\
& \left.+R_{T}\left(\frac{\Delta C^{\prime}}{K_{C} S_{C}}\right)\left(\frac{\Delta H^{\prime}}{K_{H} S_{H}}\right)\right]^{\frac{1}{2}}
\end{aligned}
$$

Şekil 2: CIEDE 2000 renk formülü $\left(\mathrm{TP}_{00}\right)^{1}$

$$
\begin{aligned}
& \mathrm{TP}_{00}=\left[\left(\frac{L_{B}^{\prime}-L_{W}^{\prime}}{\mathrm{K}_{L} S_{L}}\right)^{2}+\left(\frac{\mathrm{C}_{B}^{\prime}-C_{W}^{\prime}}{K_{C} S_{C}}\right)^{2}+\left(\frac{H_{B}^{\prime}-H_{W}^{\prime}}{K_{H} S_{H}}\right)^{2}\right. \\
& \left.+R_{T}\left(\frac{C_{B}^{\prime}-C_{W}^{\prime}}{K_{C} S_{C}}\right)\left(\frac{H_{B}^{\prime}-H_{W}^{\prime}}{K_{H} S_{H}}\right)\right]^{1 / 2}
\end{aligned}
$$

\begin{tabular}{|c|c|c|c|c|}
\hline Materyal/Üretici firma & Tip & İçerik & $\begin{array}{l}\text { Doldurucu wt/ } \\
\text { vol \% }\end{array}$ & Lot \\
\hline $\begin{array}{l}\text { G-Aenial Anterior (A2), } \\
\text { (GC Corp, Tokyo, Japan) }\end{array}$ & $\begin{array}{l}\text { Mikrohibrit } \\
\text { Kompozit }\end{array}$ & $\begin{array}{l}\text { UDMA, dimetakrilat ko-monomers, } \\
\text { prepolimerize organik doldurucu, } \\
\text { silika, stronsiyum, lanthanoid flo- } \\
\text { rid, fumed silika }(0,1-17 \mu \mathrm{m})\end{array}$ & $76 / 63$ & $190603 \mathrm{~B}$ \\
\hline $\begin{array}{c}\text { Estelite } \Sigma \text { Quick (A2), } \\
\text { (Tokuyama Dental, Tokyo, } \\
\text { Japan) }\end{array}$ & $\begin{array}{l}\text { Submikron } \\
\text { dolduruculu } \\
\text { kompozit }\end{array}$ & $\begin{array}{c}\text { Spherikal submikron doldurucu } \\
(0,1-0,3 \mu \mathrm{m}) \text { Bis-GMA, TEGDMA, } \\
\text { silika-zirkonia }\end{array}$ & $82 / 71$ & $271 E 79$ \\
\hline $\begin{array}{l}\text { Omnichroma } \\
\text { (Tokuyama Dental, Tokyo, } \\
\text { Japan) }\end{array}$ & $\begin{array}{l}\text { Supra-nano } \\
\text { dolduruculu } \\
\text { kompozit }\end{array}$ & $\begin{array}{l}\text { UDMA, TEGDMA, Uniform boyutta } \\
\text { supra-nano spherikal doldurucu } \\
\text { (260nm spherical SiO2-ZrO2), } \\
\text { kopmpozit doldurucu (260nm } \\
\text { spherikal SiO2-ZrO2) }\end{array}$ & $79 / 68$ & 021E10 \\
\hline
\end{tabular}

Tablo 1: Çalıșmada kullanılan kompozit çeșitleri, üretici firma ve kompozisyonları

\section{İstatistik analiz}

Çalışmada verilerin normalliği Kolmogrov-Smirnov testi ile belirlendi ve parametrik testler yapıldı $(p>0.05)$. Elde edilen veriler SPSS istatistik programı (Version 22.0, SPSS Inc., Chicago, Illinois, ABD) kullanılarak paired $t$ testi, tek yönlü varyans analizi (OneWay ANOVA) ve Faktöriyel ANOVA testleri ile analiz edildi $(\alpha=.05)$.

\section{BULGULAR}

Bu çalışmada $\Delta \mathrm{E}_{00}$ 'nin algılanabilir eşik değeri 0,8 olarak belirlendi ve $\Delta \mathrm{E}_{00}>0,8$ olduğunda gözle alg1lanabilir renk değişimi olarak kabul edildi. $\Delta \mathrm{E}_{00}$ için kabul edilebilir eşik değeri ise 1,8 olarak belirlendi ve $\Delta \mathrm{E}_{00}>1,8$ değerleri, klinik olarak kabul edilemez renk değişimleri olarak kabul edildi. ${ }^{18}$ Kahvede bekletme sonrası kompozit rezin örneklerde $\Delta \mathrm{E}_{00}$ renk değișim değerleri 3,28 ile 6,28 arasında ve klinik olarak kabul edilemez düzeyde tespit edildi. İncelenen materyaller arasında en yüksek renk değişimi Omnichroma kompozit rezin grubunda $(\mathrm{p}<0.05 ; \mathrm{p}=0.00)$, en düşük renk değişimi ise Estelite $\Sigma$ Quick kompozit rezin grubunda bulundu ( $\mathrm{p}<0.05 ; \mathrm{p}=0.00$ ) (Tablo 2).

Salas ve ark., tarafından yapılan bir çalışmada kompozit rezinlerin CIEDE 2000 formülüne göre translusensi algılanabilirlik ve kabul edilebilirlik eşikleri sirasıly $\% 50: \% 50$ TPT (algılanabilirlik) 0.62 ve TAT (kabul edilebilirlik) 2.62 olarak belirtilmiştir. ${ }^{1} \mathrm{Bu}$ ça- 
lıșmada da bu eșik değerler temel alınarak kahvede bekletme sonrası kompozit rezin örneklerde klinik olarak kabul edilemeyecek sınırlarda TP değerleri (7,87-12,9) gözlendi (Tablo 3). Faktöriyel ANOVA testi sonuçlarına göre kahve ile renklendirme önce ve sonrasında TP değerlerinde kompozit rezin grupları arasında farklılıklar tespit edildi. Hangi gruplar arasında farklılıkların olduğu Tukey HSD testi ile belirlendi. Kompozit rezinlerin kendi içinde TP değerleri karşılaştırması ise paired t testi ile yapıldı. Kahve ile renklendirme öncesinde Omnichroma kompozit rezin grubu incelenen materyaller arasında en yüksek TP değerleri gösterirken $(\mathrm{p}<0.05 ; \mathrm{p}=0.00)$, en düşük TP değerleri ise Estelite $\Sigma$ Quick kompozit re- zin grubu gösterdi $(p<0.05 ; p=0.00)$. Kahve ile renklendirme sonrasında Omnichroma kompozit rezin grubu incelenen materyaller arasında en yüksek TP değeri gösterdi $(p<0.05 ; p=0.00)$. G-Aenial Anterior ve Estelite $\Sigma$ Quick kompozit rezin grupları benzer TP değerleri gösterdi ( $p>0.05)$. Kahve ile renklendirme sonrası Omnichroma kompozit rezin grubunun TP değerleri anlamlı artıș gösterirken, G-Aenial Anterior kompozit rezin grubunun TP değerleri anlamlı derecede azalma gösterdi ( $<<0.05 ; p=0.001, p=0.001$ sirasiyla). Kahve ile renklendirme Estelite $\Sigma$ Quick kompozit rezin grubunun TP değerlerini etkilemedi ( $p>0.05 ; p=0,615$ ) (Tablo 3).

Tablo 2: Kompozit rezin örneklerinin kahve ile renklendirme sonrası CIEDE 2000 renk sistemine göre renk değişim $\left(\Delta \mathrm{E}_{00}\right)$ ortalama ve standart sapma değerleri

\begin{tabular}{|c|c|}
\hline Kompozit Rezin & Ort \pm std \\
\hline G-Aenial Anterior & $3,8 \pm 0,46^{\mathrm{a}}$ \\
\hline Estelite $\Sigma$ Quick & $2,65 \pm 0,61^{\mathrm{b}}$ \\
\hline Omnichroma & $6,28 \pm 0,6^{\mathrm{c}}$ \\
\hline
\end{tabular}

*Aynı harfi içermeyen gruplarda istatistiksel olarak farklılık belirlenmiştir.

Tablo 3: Kompozit rezin örneklerinin kahve ile renklendirme öncesi ve sonrası CIEDE 2000 formulüne göre ortalama ve standart sapma TP (translüsensi parametresi) değerleri ve karşılaştırılmalı sonuçları

\begin{tabular}{|c|c|c|c|}
\hline Kompozit Rezin & Kahve öncesi & Kahve sonrası & p \\
\hline G-Aenial Anterior & $8,82 \pm 0,35^{\mathrm{A}}$ & $7,87 \pm 0,46^{\mathrm{X}}$ & $>0.05$ \\
\hline Estelite $\Sigma$ Quick & $8,2 \pm 0,29^{\mathrm{B}}$ & $8,06 \pm 0,58^{\mathrm{X}}$ & $>0.05$ \\
\hline Omnichroma & $11,17 \pm 0,53^{\mathrm{C}}$ & $12,9 \pm 0,88^{\mathrm{Y}}$ & $<0.05$ \\
\hline
\end{tabular}

*Büyük harfler her bir sütundaki değerler arasındaki ilişkiyi ifade etmektedir. Aynı harfleri alanlar arasında fark yoktur.

${ }^{*}$ p değeri her bir kompozit rezin grubunun kahve ile renklendirme öncesi ve sonrası TP değerleri arasındaki farkı ifade etmektedir. p <0,05 ise fark bulunmaktadır.

\section{TARTIŞMA}

Bu çalışmada kahve ile renklendirmenin kompozit rezin örneklerde renk değişimine ve TP'ne etkisi araștırıldı. Çalışmanın, kahvede bekletme sonrası kompozit rezin örneklerinde renk değişimine ve TP'ne etki etmeyeceği yönündeki hipotezi reddedildi.

Klinisyenin, ağız boşluğunun sınıf III veya sınıf IV restorasyon üzerindeki karanlık görsel etkisini veya diş yapısı üzerindeki yoğun renk değişimlerini maskelemeye çalışmalıdır. Bu sorunların üstesinden gelmek için dental kompozit rezinlerin opak ve dentin tonları üretilmiştir. ${ }^{19}$ Özellikle ön bölgede bulunan kompozit rezin restorasyonların renk stabilitesi önem arz etmektedir. Kompozit rezin restorasyonların renklenmesi estetik başarısızlık olarak kabul edil- mekte ve çoğu zaman restorasyonun yenilenmesi ile giderilebilmektedir. Bu da hem hasta hem de hekim için ekstra maliyet ve zaman gereksinimi anlamına gelir. ${ }^{20} \mathrm{Bu}$ çalışmada renk farklılıkları ve TP değerleri CIEDE 2000 formulasyonu ile hesapland. Araştırmacllar CIEDE 2000 formulasyonun renk farklılıklarını değerlendirmede daha uygun olduğunu bildirmiştir. ${ }^{21}$ Bununla birlikte CIEDE 2000 formülünün, CIELAB ve CMC (1:1) gibi diğer formüllere kıyasla diş hekimliğinde görsel verilerde iyileștirilmiş olduğu belirtilmiştir. ${ }^{1}$

Çalışmamızda renklendirici solüsyon olarak seçilen kahve günlük yaşamda sıklıkla tercih edilen bir içecektir. Üreticilere göre bir kupa kahve, ortalama 15 dakikada tüketilmektedir. Kahve tercih eden kişinin günde 3,2 kupa kahve tükettiği varsayılarak 
örneklerin kahvede 48 saat bekletilmesi iki aylık kahve tüketimine karşıllı gelmektedir. ${ }^{16}$ Bu oranlar göz önünde bulundurularak kompozit rezin materyaller kahve içerisinde 12 gün bekletildi ve bu zamanın da 1 yıllık kahve tüketimine denk geleceği düşünüldü.

Kompozit rezin materyaller suyu absorbe edebildikleri için pigment içeren sıvllar kompozit rezinde renklenmeye neden olur. ${ }^{20}$ Su emilimi, çoğunlukla rezin matriksindeki doğrudan absorpsiyondan kaynaklanmaktadır. Su absorbsiyon oranı, materyalin rezin içeriği ve rezin-doldurucu ara yüzünün bağlanması ile ilişkilidir. Aşırı su emilimi, rezinin genişlemesine ve plastikleşmesine neden olur. Bu da kompozit rezinde leke penetrasyonuna ve renk değişikliğine ortam hazırlayan mikro çatlaklar veya ara yüzdeki dolgu ile matriks arasındaki ara yüzey boşlukları oluşmasına ortam hazırlar. Kahve, düşük polarietede sarı renk oluşturan maddeler içerir. ${ }^{22}$ Çalışmamızın sonuçlarına göre kahvede bekletme sonrası kompozit rezin örneklerinde klinik olarak kabul edilemeyecek sınırlarda renk değişimi $\left(\Delta \mathrm{E}_{00}\right)$ 3,28 ile 6,28 arasında değişmektedir. Bu sonuç, kahvenin kompozit rezinlerde belirgin renk değişimine neden olduğunu belirten diğer çalışmalarla uyumludur. ${ }^{20,23,24}$ Kompozit rezinlerin kahve solüsyonlarında 24 saatlik bekletme sonrası kompozit rezinler arasında anlamlı bir fark olduğu $(\mathrm{F}=5,665 \mathrm{P}=0,001)$ ve en az renklenmenin Estelite Sigma Quick kompozit rezinde oluştuğu görüldü. Cangül ve ark., yaptıkları çalıșmada 4 farklı kompozit rezin (Estelite Sigma Quick, G-Aenial, Clearfil Majesty Esthetic, Ceram X-One) ve 5 farklı kahve çeșidi (Nescafe, Ethiopia, Colombia, Veranda ve Türk kahvesi) karşılaştırılmıştır. Nescafe en fazla renklendiren solüsyon olarak, Clearfil Majesty ise en az renklenen kompozit rezin olarak tespit edilmiștir. Estelite $\Sigma$ Quick diğer kompozit rezinlere oranla daha fazla renklenme göstermiştir. ${ }^{25}$ Bizim çalışmamızda ise Estelite $\Sigma$ Quick kompozit rezinde, test edilen diğer kompozit rezinlere kıyasla daha az renk değişimi gözlendi. Bu durum test edilen diğer kompozit rezinlerin boyut ve yapısal farklılığından kaynaklanmıș olabilir. Ertaș ve ark.'nın yaptıkları çalıșma sonucunda doldurucu partiküllerin büyüklügünden kaynakll, mikrohibrit kompozit rezinlerin nanohibrit kompozit rezinlere göre daha fazla renklendiği görülmüștür. ${ }^{26}$ Saraç ve ark, inorganik doldurucu oranı yüksek olan nanohibrit kompozit rezinlerin, hibrit ve mikrohibrit kompozit rezinlere oranla renklenmeye daha dirençli olduğunu bildirmiştir. ${ }^{27}$ Kompozit rezinlerin renk stabilitesi; materyal özellikleri, yani matriks, doldurucu kompozisyonu (hacimce partiküllerin boyutu ve tipi), matriks doldurucu ara yüzü ve polimerizasyon derecesine (kalan reaksiyona girmemiş karbon-karbon bağlarının oranı) bağlıdır. ${ }^{28}$ Bir materyalin yüzey özellikleri de (parlaklığı, yüzey yapısı ve yüzey eğimi) o materyalin ıșık geçirgenliğini etkileyen faktör- lerdendir. Materyalin ışığı geçirebilmesi için, ışığın dağılımını engelleyecek derecede yüzey kusurları ve pörözite olmamalıdır. ${ }^{29}$ Çalışmamızda bu gibi faktörlerin elimine edilmesi amaciyla örnek yüzeylerinin standardizasyonu sağlandı ve tüm örneklerin yüzeyi aynı şekilde polisajlandı.

Translüsensi, materyalin ışığı geçirmesi sonucu arka planın görünmesi ve kısmi opaklık veya tam opaklık ile tam şeffaflık arasındaki bir durum olarak tanımlanabilir. ${ }^{30}$ TP için yüksek değerler materyalin daha fazla translüsensiye sahip olduğunu ifade eder. Eğer materyal tamamen opaksa, bu parametrenin değeri sıfırdır. ${ }^{31,32}$ Çalışmamızda kompozit rezin materyallerin TP değerleri 7,87 ile 12,9 arasında değişmektedir. Gelen ışığın materyal tarafından absorbe olması ya da geçme miktarı yani materyalin translusensi özelliği; matriks ve doldurucu birleșimi, inorganik doldurucu partiküller ile matriks faz arasındaki kırılma indeks farkl, doldurucu büyüklükleri ve partikül boyutu oranları gibi faktörlerle değişkenlik gösterebilir. $^{29,33}$

Restoratif materyal küçük partiküllü ise (yaklaşık 0.1 $\mu \mathrm{m}$. çapında) ışığı daha iyi geçirir. Büyük çapta partiküllere sahip materyaller (yaklaşık $10 \mu \mathrm{m}$. çapında) ise ışığı daha az geçirir ve daha opak görünürler. Bununla birlikte materyalin partikül sayısı da önemlidir. Materyal büyük partiküllü olmasına rağmen hacim bașına düșen partikül sayısı az ise ıșığın daha az saçılmasına ve opasitenin azalmasına neden olur. $^{34}$ Absorbe olan, yansıyan veya geçen ışığın miktarı materyalin kimyasal özelliklerine bağlı olarak da değişebilmektedir. Bu yüzden de farklı kimyasal yapılardaki restoratif materyallerin renkleri aynı olsa dahi ışığı yansıtması veya absorbe etmesi birbirinden farklı olmaktadır. Renk özellikleri, malzemenin özelliklerinin ve bileşiminin bir sonucudur. Omnichroma'nın bileşimi, $260 \mathrm{~nm}$ 'lik bir partikül boyutunda supra -nano küresel silikon dioksit $\left(\mathrm{SiO}_{2}\right)$ ve zirkonyum dioksit $\left(\mathrm{ZrO}_{2}\right)$ doldurucu maddesinden oluşur. Araștırmacılar tarafından, Bis-GMA'nın UDMA ve TEGDMA'ya oranla translusent özelliğinin fazla olduğu bildirilmiștir. ${ }^{35}$ Sebebi olarak, Bis-GMA'nın kırılma indisi ile silika doldurucunun kırılma indisinin yakın olmasını bildirmişlerdir. Ancak çalışmamızda Bis-GMA içermeyen Omnichromanın yüksek TP değerlerinde olması içerikte yer alan monomer ve doldurucular ile ilgili olabilir. Üreticiye göre Omnichroma pigment içermez ve renk özellikleri, kompozit rezinin optik özelliklerini kontrol etmek amacıyla akıllı bir kromatik teknoloji olan yapısal renklere dayanır. ${ }^{36}$ Renk pigmentlerin olmaması ve polimerizasyon derecesi (kalan tepkimeye girmemiş karbon-karbon bağlarının oranı) Omnichroma kompozit rezinin daha fazla translusensi ve renk değiștirme faktörlerinden biri olabilir. Çalıșmamızda ilk ölçülen TP değerleri G-Aenial Anterior (mikrohibrit) içerik- 
li kompozit rezinde daha az gözlenirken; Estelite $\Sigma$ Quick (submikron), Omnichroma (supra-nano doldurucu içerikli) daha yüksek TP değerleri gözlendi. Kahve ile renklendirme sonrası materyallerin içerik farklılıkları ve renklenme durumu TP değerlerinde değişiklikler göstermesine neden olabilir. Kompozit rezinler arasındaki farklılıklar materyallerin kimyasal yapı, partikül sayısı veya partiküllerin çapına bağlanabilir. $^{29}$

Araştırmacılar, kompozit rezinde yer alan TEGDMA'ya Bis-GMA eklenerek rezinin kırılma indisinin artarak silika doldurucununkine yaklaştığını ${ }^{37}$ ve silika doldurucu sistemle optik uyumunun daha iyi olacağını bildirmişlerdir. ${ }^{35}$ Estelite $\Sigma$ Quick kompozit rezinin kahve sonrası renk değișimi en az ve translusensi değerinde belirgin bir değișme olmamıștır. Bu durum submikron doldurucu oranının farklılığından kaynaklanmış olabilir. Yu ve Lee, ${ }^{31} \mathrm{~L}$ değeri ve translüsensi arasında anlamlı ilișki olduğunu belirtmiştir. Benzer bir çalıșmada da translüsensi değeri en yüksek materyalin L değerlerinin yüksek olduğu bildirilmiştir. ${ }^{11} \mathrm{Bu}$ çalışmada en yüksek translüsens değeri Omnichroma supra-nanodoldurucu içerikli kompozit rezin grubunun aynı zamanda en büyük L değerlerine sahip olduğu bulunmuştur. Yaşlandırma işleminden sonra kompozit rezin materyallerde TP değerlerinin azaldığını bildiren araștrımacılar oldugu gibi, ${ }^{29}$ arttığını da bildiren araștırmacılar vardır. ${ }^{38}$ Bizim çalıșmamızda kahve ile renklenme sonrası Omnichroma kompozit rezin grubunun TP değerleri artarken diğer kompozit rezinlerde azaldığı gözlendi.

Bu çalışma, kompozit rezinlerde renk ve translusensi özelliğinin bilinmesiyle yapılacak restorasyonlarda renk seçimini basitleştirebileceğini ve daha kolay ve daha az zaman alıcı hale getirebileceğini önermektedir. Ayrıca, bu malzemeler zorlu ve karmașık renk eşleştirme durumlarını kolaylaştırabilir. Kompozit rezinler ve çevreleyen dental diș yapıları arasındaki nihai renk uyumsuzlukları telafi edilebilir, bu da iyileștirilmiș estetik görünümde olan doğala benzer restorasyonlara yol açar. ${ }^{39}$ Omnichromanın tek renk olması, geniş renk seçeneği olan kompozit rezinlerdeki renk eșleștirme prosedürlerine olan bağımlılığı azaltmaya imkan verebilir. ${ }^{40}$

Restoratif materyaller en iyi klinik çalışmalarla değerlendirilebilmektedir. Hastaların uzun takip süresi ve etik gereklilikler klinik çalışmaların yapılmasını sınırlamaktadır. ${ }^{41,42}$ Ağız ortamında tükürük, sıcaklık değişiklikleri ve $\mathrm{pH}$ seviyeleri de kompozit rezin materyallerde uzun vadeli renk stabilitesini ve translusensi değerlerini etkileyebilir. Özellikle kompozit rezin materyallerin optik özellikleri ile ilgili daha çok çalışmaya ihtiyaç vardır.

\section{SONUÇ}

$\mathrm{Bu}$ çalışmanın limitasyonları dahilinde, kompozit rezin materyallerde kahvede bekletme sonrası optik özellikler üzerinde kullanılan materyalin içerik farklılıklarına göre değişiklikler olabileceği tespit edildi. Yoğun kahve tüketimi olan bireylerde estetik bölgelerde kullanılacak kompozit rezinlerin renk stabilitesi hakkında hekimin bilgi sahibi olması uzun ömürlü restorasyonlar için önem arz etmektedir.

\section{KAYNAKLAR}

1. Salas M, Lucena C, Herrera LJ, Yebra A, Della Bona A, Pérez MM. Translucency thresholds for dental materials. Dent Mater. 2018;34:1168-74.

2. ElSayad II. Color and translucency of finished and unfinished esthetic restorative materials after staining and bleaching. Saudi Dent J. 2018;30:219-25.

3. Çelik N, Sağsöz O, Gündoğdu M. Farklı içeceklerin posterior kompozitlerin renk değişikliği ve yüzey pürüzlülüğü üzerine etkisinin değerlendirilmesi. J Dent Fac Atatürk Uni. 2017;27:27-33.

4. Spina DRF, Grossi JRA, Cunali RS, Baratto Filho F, Cunha LF da, Gonzaga CC, et al. Evaluation of discoloration removal by polishing resin composites submitted to staining in different drink solutions. Int Sch Res Not. 2015;2015:1-5.

5. Kazemi Yazdi H, Nasoohi N, Benvidi M. In vitro efficacy of listerine whitening mouthwash for color recovery of two discolored composite resins. Front Dent. 2019;16:186.

6. Ruchi Gupta, Arvind Bhatheja, Ashvin G John, Midhun Ramchandran, Afnan Ajaz Raina AB, Behera A, et al. Effect of beverages on color stability of resin composites: An in vitro study. Int J Appl Dent Sci. 2019;5:925.

7. Müdüroğlu R, Çongara Kivrak T, Nalçaci A. Renk belirlenmesinde kullanılan yöntem ve cihazlar. Cumhur Dent J. 2018;21:61-9.

8. Fani G, Vichi A, Davidson CL. Spectrophotometric and visual shade measurements of human teeth using three shade guides. Am J Dent. 2007;20:142-6.

9. Chen H, Huang J, Dong X, Qian J, He J, Qu X, et al. A systematic review of visual and instrumental measurements for tooth shade matching. Quintessence Int. 2012;43:649-59.

10. Yildirim B, Recen D, Tekeli Simsek A. Effect of cement color and tooth-shaded background on the final color of lithium disilicate and zirconia-reinforced lithium silicate ceramics: An in vitro study. J Esthet Restor Dent. 2020;10.1111/jerd.12611.

11. Gül P, Akgül N. Farklı kompozit rezinlerin translüsensi ve maskeleme özelliklerinin karşılaştırılması. Dent Fac Atatürk Uni. 2013;21:30-6.

12. Commission Internationale de L’Eclairage. CIE 15: Technical Report: Colorimetry 2004; 552.

13. Pérez MM, Ghinea R, Ugarte-Alván LI, Pulgar R, Paravina RD. Color and translucency in silorane-based resin composite compared to universal and nanofilled composites. J Dent. 2010;38:110-6.

14. Johnston WM, Reisbick MH. Color and translucency changes during and after curing of esthetic restorati- 
ve materials. Dent Mater. 1997;13:89-97.

15. Lee YK, Lim BS, Rhee SH, Yang HC, Powers JM. Color and translucency of A2 shade resin composites after curing, polishing and thermocycling. Oper Dent. 2005;30:436-42.

16. Güler E, Yücel A, Gönülol N, Yılmaz F, Ersöz E. Farklı içeceklerde bekletilen kompozit rezinlerin renk stabilitelerinin karşılaştırılması. J Dent Fac Atatürk Uni. 2013;21:24-9.

17. Harorlı OT, Barutcigil C. Color recovery effect of commercial mouth rinses on a discolored composite. J Esthet Restor Dent. 2014;26:256-63.

18. Paravina RD, Ghinea R, Herrera LJ, Bona, AD, Igiel C, Linninger M, et al. Color difference thresholds in dentistry. J Esthet Restor Dent. 2015;27:1-9.

19. Haas K, Azhar G, Wood DJ, Moharamzadeh K, van Noort R. The effects of different opacifiers on the translucency of experimental dental composite resins. Dent Mater. 2017;33:310-6.

20. Mutlu ȘN, Tuncdemir MT. Beyazlatıcı ağız gargarasının renklendirilmiş kompozit rezinin renk değișimine ve yüzey pürüzlülüğüne etkisi. Selcuk Dent J. 2020;7:435-9.

21. Ghinea R, Pérez MM, Herrera LJ, Rivas MJ, Yebra A, Paravina $\mathrm{RD}$. Color difference thresholds in dental ceramics. J Dent. 2010;38:57-64.

22. Malekipour MR, Sharafi A, Kazemi S, Khazaei S, Shirani F. Comparison of color stability of a composite resin in different color media. Dent Res J (Isfahan). 2012;9:441-6.

23. Zajkani E, Abdoh Tabrizi M, Ghasemi A, Torabzade $\mathrm{H}$, Kharazifard M. Effect of staining solutions and repolishing on composite resin color change. JIDA. 2013;25:139-46.

24. Poggio C, Vialba L, Berardengo A, Federico R, Colombo M, Beltramiet R, et al. Color Stability of New Esthetic Restorative Materials: A Spectrophotometric Analysis. J Funct Biomater. 2017;8:26.

25. Cangül S, Adıgüzel Ö, Ünal S, Tekin S, Sonkaya E, Erpaçal B. Investigation of the color stability of kept composite resins in different coffee types. Yeditepe Dent J. 2020;16:117-22.

26. Ertaş E, Güler AU, Yücel AC, Köprülü H, Güler E. Color stability of resin composites after immersion in different drinks. Dent Mater J. 2006;25:371-6.

27. Saraç D, Saraç YȘ, Külünk Ș, Kural Ç, Külünk T. Farklı inorganik dol- durucu içerikli kompozit rezinlerin renk sabitliği üzerinde polisaj yön- temlerinin ve yüzey verniği uygulamasının etkisi. GÜ Diş Hek Fak Derg. 2006;23:169-75.

28. Tuncdemir AR, Güven ME. Effects of fibers on color and translucency changes of bulk-fill and anterior composites after accelerated aging. Biomed Res Int. 2018;2018:2908696.

29. Turgut S, Bağıș B, Bağıs YH, Korkmaz FM, Tüzüner T, Baygın Ö. Restoratif materyallerin translüsensi özelliklerinin değerlendirilmesi. AÜ Diș Hek Fak Derg. 2011;38:18-20.

30. Ryan EA, Tam LE, McComb D. Comparative translucency of esthetic composite resin restorative materials. J Can Dent Assoc. 2010;76:a84.

31. Yu B, Lee YK. Influence of color parameters of resin composites on their translucency. Dent Mater. 2008;24:1236-42.

32. Yu B, Lee YK. Translucency of varied brand and shade of resin composites. Am J Dent. 2008;21:229-32.

33. Piccoli YB, Lima VP, Basso GR, Salgado VE, Lima GS, Moraes RR. Optical stability of high-translucency resin-based composites. Oper Dent. 2019;44:536-44.

34. Heffernan MJ, Aquilino SA, Diaz-Arnold AM, Haselton DR, Stanford CM, Vargas MA. Relative translucency of six all-ceramic systems. Part I: core materials. J Prosthet Dent. 2002;88:4-9.

35. Azzopardi N, Moharamzadeh K, Wood DJ, Martin N, van Noort R. Effect of resin matrix composition on the translucency of experimental dental composite resins. Dent Mater. 2009;25:1564-8.

36. Pereira Sanchez N, Powers JM, Paravina RD. Instrumental and visual evaluation of the color adjustment potential of resin composites. J Esthet Restor Dent. 2019;31:465-70.

37. Mikhail SS, Schricker SR, Azer SS, Brantley WA, Johnston WM. Optical characteristics of contemporary dental composite resin materials. J Dent. 2013;41:771-8.

38. Lu H, Powers JM. Color stability of resin cements after accelerated aging. Am J Dent. 2004;17:354-8.

39. Durand LB, Ruiz-López J, Perez BG, Ionescu AM, Carrillo-Pérez F, Ghinea R, et al. Color, lightness, chroma, hue, and translucency adjustment potential of resin composites using CIEDE2000 color difference formula. J Esthet Restor Dent. 2020;10.1111/jerd.12689.

40. Morsy A, Gamal W, Riad M. Color matching of a single shade structurally colored universal resin composite with the surrounding hard dental tissues. EDJ. 2020;66:2721-7.

41. Nikaido T, Kunzelmann KH, Chen H, Ogata M, Harada N, Yamaguchi S, et al. Evaluation of thermal cycling and mechanical loading on bond strength of a self-etching primer system to dentin. Dent Mater. 2002;18:269-75.

42. Koyuturk AE, Kusgoz A, Ulker M, Yeșilyurt C. Effects of mechanical and thermal aging on microleakage of different fissure sealants. Dent Mater J. 2008;27:795801. 